\title{
Method for assessing Maintenance and maintainability in residential buildings - one of the basic categories of the social aspect of sustainable construction
}

\author{
Aleksandra Radziejowska \\ AGH University of Science and Technology in Cracow, Faculty of Mining and Geoengineering, Department of Geomechanics, Civil \\ Engineering and Geotechnics, Al. Mickiewicza 30, 30-059 Cracow, POLAND REPUBLIC \\ e-mail: aradziej@agh.edu.pl
}

\section{SUMMARY}

The article presents a proposal for a method of evaluation of one of the six main categories describing the social aspect of sustainable construction, category $K_{5}$ maintenance and maintainability. The selection of proper criteria for the category assessment is based, among others, on standard EN 16309+A1:2014-12. The article presents ways of assessing different characteristics by describing the category of maintenance and maintainability. Literature studies and numerous surveys are carried out in order to determine threshold values as well as the importance of the features characterizing the examined category. Then the way of obtaining an aggregated assessment of the examined category is presented. The obtained result is then compared with an identical reference object, enabling so to determine the degree of fulfilment of the social properties contained in the analysed category. Ultimately, an analogous assessment for each of the six categories describing the social aspect of sustainable construction will make it possible to determine the social quality of residential buildings and to classify them according to the characteristics studied.

KEY WORDS: maintenance; residential building; social aspect; sustainable construction; evaluation.

\section{INTRODUCTION}

Construction is one of the most important areas of economic and social life, using extensively natural resources and has an impact on the environment: during construction production, which results in services and buildings, and also during their operation. The analyses, developed by the Technical Committee CEN/TC 350 Sustainability of construction works, have been carried out for several years. The committee's scope of work includes designing 
standards for sustainable construction (SC) broken down into three interpenetrating aspects: environmental, social, and economic [1], [2]. Three basic standards appeared in the area of the social properties of the construction. The first of them, the standard [3] is given general principles and requirements for the assessment of buildings in terms of environmental, social, and economic properties, taking into account the technical characteristics and functionality of the building. The next standard [4] is distinguished from the following categories characterizing the social utility properties of sustainable construction: $K_{1}$ - accessibility; $K_{2}-$ adaptability; $K_{3}$ - health and comfort; $K_{4}$ - impact on the neighbourhood; $K_{5}$ - maintenance and maintainability; $K_{6}$ - safety and security. However, the most important norm regarding the social aspect is [5], which sets out the methods and requirements for assessing the social performance of buildings taking into account their technical characteristics and functionality. However, despite the high level of detail, none of the standards contains threshold values, classes, weights, or reference points for measuring the properties of individual social indicators. Moreover, the author did not find in the available literature any works dealing with this subject comprehensively.

The article presents a complete characterization of the basic category highlighted in [4], $K_{5}$ maintenance and maintainability. This paper presents the author's proposal for a $K_{5}$ category assessment of the necessary maintenance policy measures. The features that should be assessed as well as the manner and scale of their assessment (uniform five-point scale, where 5 is the highest mark) are also presented. Then, a method is proposed to be used which will provide an assessment of the social aspect of category $K_{5}$ in the form of a single-number indicator informing about the degree of fulfillment of the assessed features in relation to the reference object (constituting the basis for comparison of the rated features, meeting current regulations and legal requirements). This publication is part of the work which aims at presenting a comprehensive method of assessing the social aspect of sustainable construction [6].

\section{ASSESSMENT METHOD}

\subsection{SYSTEMATICS OF RESEARCH}

Maintenance and maintainability is one of the six basic categories of social evaluation of buildings. It is widely known that a properly conducted maintenance policy of a building structure has a significant impact on the length of its life and is a basic element of differentiating properties. With appropriate care and prevention measures, it is possible to significantly affect both, the quality of use of the building, and the length of its life, without constantly carrying out the costly refurbishment.

The assessment of a building for category $K_{5}$ is obtained by calculating an add-on function consisting of subcategory assessments, as shown in chapter 4 . The examined features are expressed in various scales and measures. In order to simplify the application of the method, a five-point assessment scale was adopted for all the examined features. The 5 -element scale (also known as the Likert scale) is one of the most popular scales. The range of this scale allows the score to be varied and at the same time, it is considered convenient for the evaluator.

Assessment of component $K_{5}$ is carried out according to the following procedure:

1. Identification of features relevant to the assessment of activities related to the maintenance and maintainability of buildings. 
A. Radziejowska: Method for assessing Maintenance and maintainability in residential buildings - one of the basic categories of the social aspect of sustainable construction

2. Development of an evaluation model.

3. Determination of threshold values, i.e. requirements to be met by the building under examination for its use during maintenance and servicing works.

4. Determination of how the individual characteristics of a $K_{5}$ category are assessed.

5. Determination of the importance of the characteristics to be taken into account in the assessment through user surveys and expert questionnaires.

6. Assessing of the building by using a multi-criteria analysis.

The following chapters present in detail the rules for the selection of criteria assessment measures and the construction of the model in order to calculate the assessment of residential buildings according to category $K_{5}$.

\subsection{CHARACTERISTICS OF THE CATEGORY $K_{5}$ - MAINTENANCE AND MAINTAINABILITY}

Features characterizing the maintenance and maintainability category are established based on developed standards for sustainable construction, in particular standards [5], [4]. Two subcategories are adopted, refined by a total of five assessed features characterizing the presented category.

The description of the proposed features for the assessment of $K_{5}$ category should begin with defining the basic term, maintenance. Maintenance of a building object consists of undertaking actions aimed at ensuring proper technical condition and usability during its use, so as not to allow excessive deterioration of performance and technical efficiency [7], [8], [9]. These activities result directly from the deteriorating parameters and operational characteristics of the facility over time. Hence the need to conduct appropriate and systematic activities aiming at the proper maintenance of the building, include:

- maintenance and maintainability,

- refurbishment works,

- works related to the adapting of the facility to new requirements,

- demolition works (when the reconstruction of the building is unprofitable) [10].

Table 1 shows the division of the $K_{5}$ category 'Maintenance and maintainability' into two subcategories $K_{51}$ and $K_{52}$. Individual subcategories are assessed by criteria marked in the next part of the article with symbols $K_{511} \div K_{522}$. For the assessment of the criteria, a discrete five-point scale is adopted, in which the most advantageous solution will take the highest value equal to 5 .

Table 1 Division of category $K_{5}$ into subgroups $K_{51}$ and $K_{52}$ and criteria for assessing them $K_{511} \div K_{522}$

\begin{tabular}{lll}
$\boldsymbol{K}_{\mathbf{5 1}} \begin{array}{l}\text { Maintenance } \\
\text { operations }\end{array}$ & $\boldsymbol{K}_{\mathbf{5 1 1}}$ & $\begin{array}{l}\text { Frequency and duration of regular maintenance (e.g. washing windows, } \\
\text { facades, staircases, painting a staircase, elevator maintenance, snow removal }\end{array}$ \\
\cline { 2 - 3 } & $\boldsymbol{K}_{\mathbf{5 1 2}}$ & Safety of users during work \\
\cline { 2 - 3 } & $\boldsymbol{K}_{\mathbf{5 1 3}}$ & Maintainability \\
\hline \hline \begin{tabular}{l}
$\boldsymbol{K}_{\mathbf{5 2}} \begin{array}{l}\text { Renovation and } \\
\text { refurbishment } \\
\text { works }\end{array}$ \\
\cline { 2 - 3 }
\end{tabular} & $\boldsymbol{K}_{\mathbf{5 2 1}}$ & Frequency/need to carrying out repair and refurbishment works \\
\cline { 2 - 3 } & & $\begin{array}{l}\text { Possibility to use the building while performing renovation and } \\
\text { refurbishment }\end{array}$ \\
\hline
\end{tabular}


A. Radziejowska: Method for assessing Maintenance and maintainability in residential buildings - one of the basic categories of the social aspect of sustainable construction

\section{SETTING CRITERIA THRESHOLD VALUES}

\subsection{DETERMINING THE SCALE OF PARAMETER VALUES CHARACTERIZING SUBCATEGORY $K_{51}$}

Subcategory $K_{51}$ is concerned with the assessment of the operating policy in the building. Maintenance works are associated with maintaining the operational continuity of the building and allowing it to ensure the proper conditions of its use. Such works consist in particular of:

- keeping clean,

- applying protective coatings (i.e., impregnation, painting),

- repairing construction elements (i.e., the removal of found damage preceded by the removal of the causes of their occurrence),

- replacement of worn installation and building components (i.e., valves, seals, fuses, doors, windows),

- changing the internal finish (i.e., replacing the tiles, decorations),

- ongoing checks on the correct operation of technical devices (following regulations).

Such actions enable proper functional maintenance of the facility, ensuring the required values of parameters and current functional characteristics (i.e. heating, energy, water supply, sewage disposal, etc.) [10].

\subsubsection{CRITERION $K_{511}$ THE FREQUENCY AND DURATION OF REGULAR MAINTENANCE}

Maintaining the good technical condition of equipment, installations, and building structures requires ongoing service and regular repairs. Thanks to properly conducted service and timely device maintenance (following the instructions), it is possible to significantly affect the durability of the building by preventing premature aging and wear of the solutions used [11], [12]. The discussed criterion $K_{511}$ is to assess the undertaken maintenance works for the proper operation of the facilities.

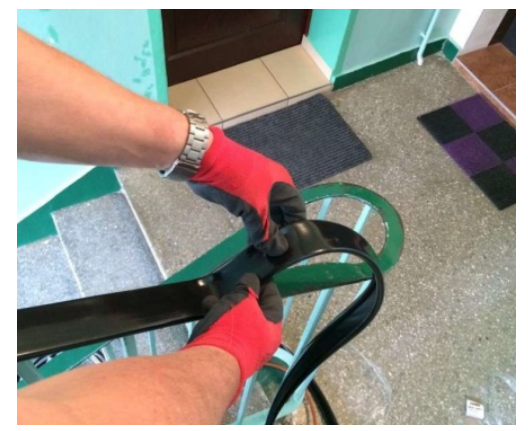

Fig. 1 Installation of rubber overlays on the handrail in the staircase

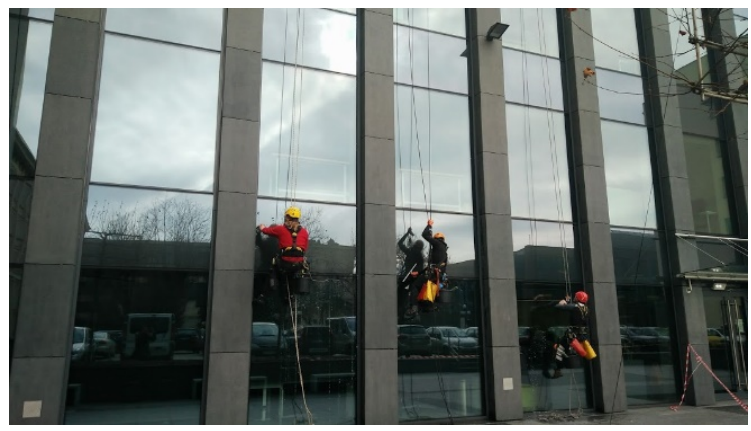

Fig. 2 Cleaning glazed surfaces, 02.2017, Cracow

Common areas such as staircase, corridors, technical rooms (i.e., boiler room, electrical switchgear), trolley, bicycle room, drying room, and multi-bay garages will be subject to particular assessment. It should also be noted that currently nanomaterials are used, which are characterized by durability and resistance to pollution. The use of modern materials with self- 
cleaning properties allows us to reduce the frequency or stop performing some activities related to maintaining cleanliness in common areas. The application of such solutions in the building in use is an incredible asset that allows us to obtain the highest rating according to criterion $K_{511}$.

Examples of modern materials are:

- paint coatings with active nano-silver elements that prevent the appearance of bacteria, mold, fungi on the surface and also have thermoregulatory properties;

- $\quad$ self-cleaning glass, covered with a special coating which breaks down the organic dirt by means of UV radiation, and thanks to its hydrophilic properties, rainwater removes dirt that then flows down the entire glass pane without creating streaks.

In the above criterion, the frequency of activities aimed at functional maintenance of the building is assessed. Among them, the following can be mentioned: cleanliness (cleaning, vacuuming, washing, etc. - Figure 1, Figure 2), conducting ongoing inspections of technical devices (maintenance/replacement of equipment elements whose service life is short, i.e., valves, gaskets, fuses, etc.), or the use of protective coatings (i.e., lubricants, impregnates, etc.) Table 2. Thanks to the above actions, the required values of parameters and operational characteristics are provided [10].

Table 2 Evaluation of criterion $K_{511}$ Frequency and duration of regular maintenance

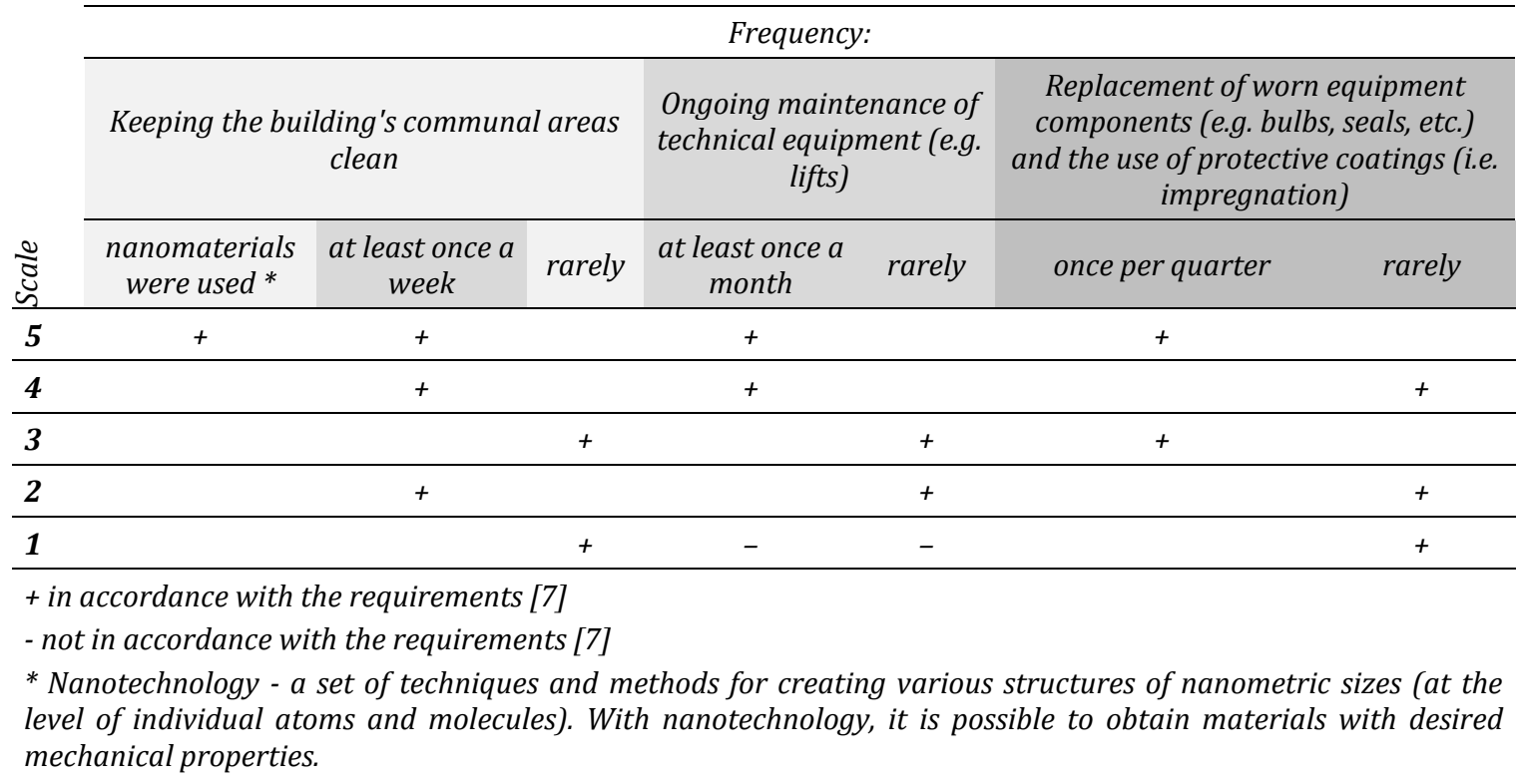

\subsubsection{CRITERION $K_{512}$ - SAFETY FOR USERS DURING MAINTENANCE AND DURATION OF REGULAR MAINTENANCE}

The aspect regarding the safety of users during maintenance works is to assess the consequences (for users) of taking technical actions to maintain the building in a state in which it will perform the required functions or restore its technical parameters in case of a fault. This criterion assesses the aspect of maintenance work related to the safety of users during their conduct (the use of appropriate safeguards, e.g. barriers, platforms, stairs, ladders for snow removal from roofs, glass washing brackets, chimney sweep benches for chimney maintenance, etc.) and the duration of these activities. The assessment summary is presented in Table 3. 
A. Radziejowska: Method for assessing Maintenance and maintainability in residential buildings - one of the basic categories of the social aspect of sustainable construction

Table 3 Evaluation of criterion $K_{512}$ Safety for users during maintenance and duration of regular maintenance

\begin{tabular}{|c|c|c|c|c|c|}
\hline \multirow[t]{2}{*}{ Scale } & \multicolumn{2}{|c|}{$\begin{array}{c}\text { Safety devices for maintenance work (e.g. railings, platforms, } \\
\text { handles, ladders, chimney sweep benches, etc.) }\end{array}$} & \multicolumn{3}{|c|}{ Length of maintenance activities } \\
\hline & are preserved & none & 1 day & 2 days & longer \\
\hline 5 & + & & + & & \\
\hline 4 & + & & & + & \\
\hline 3 & + & + & + & & + \\
\hline 2 & & + & & + & \\
\hline 1 & & + & & & + \\
\hline
\end{tabular}

\subsubsection{CRITERION $K_{513}$ - EASE OF MAINTAINABILITY}

The ease of maintenance allows thorough, regular inspections, and repair work when needed. This criterion takes into account lighting and thermal conditions, easy access to devices and installations for which regular inspections are necessary, as well as the possibility of simple replacement / repair of damaged or worn replaceable elements, i.e., bulbs, gaskets, lubricants, impregnates. Difficult access to the performance of maintenance activities may result in the lack of proper inspection, repair, or replacement, which in the long term, will affect the quality of building use and cause its faster degradation.

This aim is to assess whether there is easy access for the maintenance activities in the building - Table 4.

Table 4 Evaluation of criterion $K_{513}$ Ease of maintainability

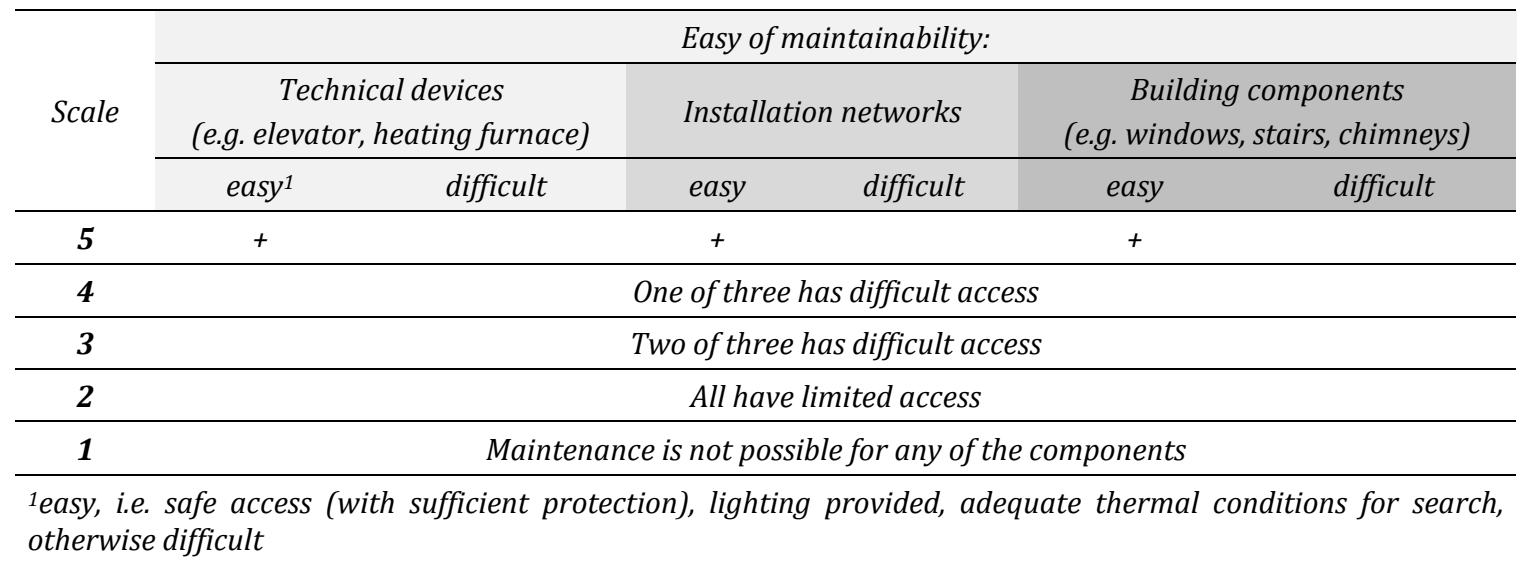

\subsection{DETERMINING THE SCALE OF PARAMETER VALUES CHARACTERIZING THE SUBCATEGORY $K_{52}$}

Refurbishment works should be understood as carrying out construction works on an existing building facility that consist in the restoration of the original condition, and are not part of permanent maintenance when it is allowed to use construction products other than the ones used in its original state [7] (e.g. replacement of roofing, boiler, etc.). Modernization works are not defined by the construction law, however, there is an official statement issued by COBS 
A. Radziejowska: Method for assessing Maintenance and maintainability in residential buildings - one of the basic categories of the social aspect of sustainable construction

(Central Office for Building Supervision - [13]) about the concept of "modernization", which accordingly should be regarded as carrying out construction or reconstruction ${ }^{1}$, or extension ${ }^{2}$ works.

The scope of this work includes renovation or modernization of:

- building connections (e.g. water supply, sewerage, gas network, etc.),

- installation in a building,

- foundations (e.g. reinforcement, insulation, drying, etc.),

- structural elements (e.g. ceilings, load-bearing walls, roof structure, stairs, etc.),

- facades (e.g. thermomodernization, painting, plasters, etc.),

- reconstruction of the functional layout of the building (e.g. sanitary facilities, entrances, and entrances to the building, etc.), [14].

In the housing development process, investment tasks consisting of the renovation and modernization of the housing substance are often found. Rehabilitation ${ }^{3}$ of urban development complexes aims at adapting the facilities to modern requirements and providing them with longer operation time (Figure 3, Figure 4). Also, the construction facility that enables compliance with legal and user requirements eliminates several environmental burdens that would occur if demolition had to be carried out.

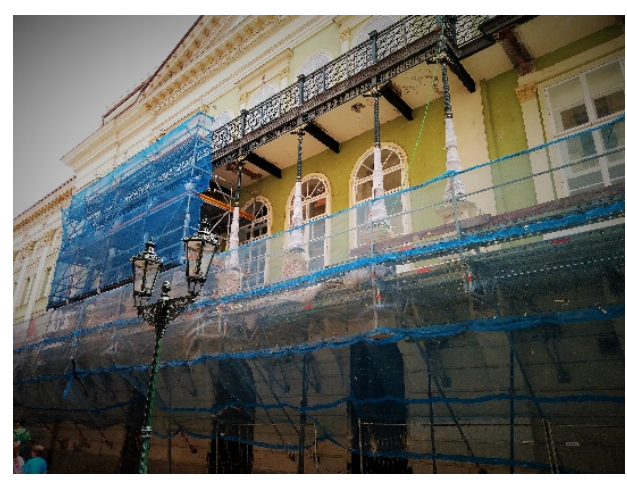

Fig. 3 Refurbishment of balconies in a historic tenement house, Prague 23.05.2016

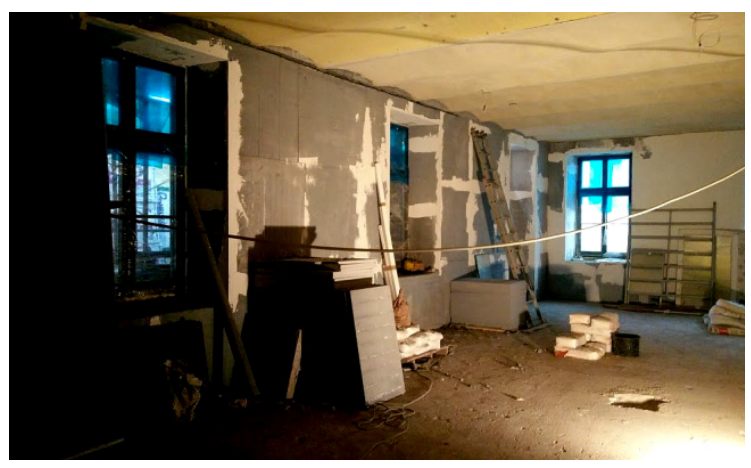

Fig. 4 General refurbishment of the tenement house, Cracow 14.04.2016

The subcategory $K_{52}$ is designed to assess the frequency of renovation work and the possibility of using the building during their progress.

\subsubsection{CRITERION $K_{521}$}

The frequency/the need of refurbishment works. Refurbishment and modernization works include replacement/addition of windows/doors; adaptation of the attic and/or basement; building insulation; painting the facade; replacement of central heating, water, and sewage installations, mechanical and electrical ventilation; demolition of walls, strengthening of the

\footnotetext{
1 performance of construction works, as a result of which there is a change in the utility or technical parameters of the existing object (e.g. change in the roof structure, enlargement of window openings, etc.), in addition to characteristic parameters, such as building surface, volume, length, width, height, number of floors [15]. This requires a building permit.

2 type of construction that results in a new part of an existing building.

3 investment activities including improving the living conditions of residents through decomposition, rehabilitation or reconstruction
} 
ceiling, staircase, etc. Refurbishment or modernization of a building is usually a large and expensive project and often involves the completion of many formalities before the work begins. Some refurbishment works require a building permit or decision on building conditions, which extends the time of their implementation and repeatedly causes trouble for property managers and owners. Well-planned works allow the efficient and lightly onerous restoration of the building to its original condition and the increase of its value in use (e.g. superstructure, extension). The frequency of refurbishment depends on many factors, and the most important are:

- age of the building,

- type of building structure,

- taking care of the technical condition of its construction during use.

The dominant attribute of this evaluation criterion is, according to the author, the age of the building. The durability of the building's elements and structure depends to a large extent on its age and the type of material used. In addition, the need for modernization (refurbishment) caused by a change in requirements (regulations) arises from the age of the building. Therefore, the age of the building under assessment will be considered in the calculation, taking into account the two most common types of structures (i.e., the traditional buildings and the so-called large-panel system/precast prefabricated concrete construction) as shown in Table 5.

Table 5 Evaluation of criterion $K_{521}$ The frequency / the need for refurbishment works

\begin{tabular}{|c|c|c|c|c|c|c|c|c|c|c|}
\hline \multirow{3}{*}{ Scale } & \multicolumn{10}{|c|}{ Age of building [years] } \\
\hline & \multicolumn{2}{|c|}{$0-15$} & \multicolumn{2}{|c|}{$16-30$} & \multicolumn{2}{|c|}{$31-45$} & \multicolumn{2}{|c|}{$46-60$} & \multicolumn{2}{|c|}{$>60$} \\
\hline & $T$ & $W$ & $T$ & $W$ & $T$ & $W$ & $T$ & $W$ & $T$ & $W$ \\
\hline 5 & + & + & + & & & & & & & \\
\hline 4 & & & & + & + & & & & & \\
\hline 3 & & & & & & + & + & & & \\
\hline 2 & & & & & & & & + & & \\
\hline 1 & & & & & & & & & + & + \\
\hline
\end{tabular}

$T$ - buildings erected in traditional technology

$W$ - system buildings (large panel)

\subsubsection{CRITERION $K_{522}$}

The usability of the building during the refurbishment tasks. Refurbishment and modernization work, depending on the objective, can be a time-consuming project, and, in most cases, during its duration, it may be accompanied by the difficulty of the building use. In criterion $K_{522}$, how major difficulties will occur during refurbishment works should be assessed. Additionally, a division according to the type of renovated building elements (e.g. ceilings, facade, etc.) is proposed as listed in Table 6. The proposed assessment of this criterion is presented in Table 7 . 
A. Radziejowska: Method for assessing Maintenance and maintainability in residential buildings - one of the basic categories of the social aspect of sustainable construction

Table 6 Structural elements in residential buildings

\begin{tabular}{|c|c|c|c|c|}
\hline \multicolumn{3}{|c|}{$\begin{array}{l}\text { Possibility of using the building during renovation and modernization } \\
\text { works due to the type of structural elements }\end{array}$} & $\begin{array}{l}\text { Difficult / } \\
\text { problematic }\end{array}$ & $\begin{array}{c}\text { Part or whole } \\
\text { building out of service }\end{array}$ \\
\hline \multirow{5}{*}{$S L A B$} & \multicolumn{2}{|c|}{ wood } & & $\checkmark$ \\
\hline & \multicolumn{2}{|l|}{ steel } & & $\checkmark$ \\
\hline & \multicolumn{2}{|c|}{ ceramic - steel } & & $\checkmark$ \\
\hline & \multicolumn{2}{|c|}{ prefabricated } & $\checkmark$ & \\
\hline & \multicolumn{2}{|c|}{ reinforced concrete } & $\checkmark$ & \\
\hline \multirow{4}{*}{$\begin{array}{l}\text { VERTICAL ELEMENTS } \\
\text { (i.e. load-bearing walls, } \\
\text { columns) }\end{array}$} & \multirow{2}{*}{$\begin{array}{l}\text { skeleton } \\
\text { structure }\end{array}$} & wood & & $\checkmark$ \\
\hline & & steel & & $\checkmark$ \\
\hline & \multirow{2}{*}{ full } & masonry & $\checkmark$ & \\
\hline & & reinforced concrete & $\checkmark$ & \\
\hline \multirow{3}{*}{ FOUNDATIONS } & \multicolumn{2}{|l|}{ stone } & & $\checkmark$ \\
\hline & \multicolumn{2}{|c|}{ reinforced concrete } & $\checkmark$ & \\
\hline & \multicolumn{2}{|c|}{ mansory } & $\checkmark$ & \\
\hline \multirow{3}{*}{ STAIRS } & \multicolumn{2}{|l|}{ wood } & & $\checkmark$ \\
\hline & \multirow{2}{*}{\multicolumn{2}{|c|}{ steel }} & & $\checkmark$ \\
\hline & reinforced concrete & & $\checkmark$ & \\
\hline \multirow{3}{*}{$\begin{array}{l}\text { ROOF } \\
\text { (truss / flat roof) }\end{array}$} & \multicolumn{2}{|l|}{ wood } & $\checkmark$ & \\
\hline & \multicolumn{2}{|l|}{ steel } & $\checkmark$ & \\
\hline & \multicolumn{2}{|c|}{ reinforced concrete } & $\checkmark$ & \\
\hline
\end{tabular}

Table 7 Evaluation of criterion $K_{522}$ The usability of the building during the refurbishment tasks

\begin{tabular}{|c|c|c|c|c|}
\hline \multicolumn{5}{|c|}{ Using the building during renovation / modernization works of the elements, i.e. } \\
\hline Scale & building connections & elevation & installations in the building & structural elements * \\
\hline 5 & + & + & + & + \\
\hline \multirow{2}{*}{4} & + & + & + & - \\
\hline & + & + & - & + \\
\hline \multirow{2}{*}{3} & + & + & - & - \\
\hline & - & - & + & + \\
\hline \multirow{2}{*}{2} & - & - & + & - \\
\hline & - & - & - & + \\
\hline 1 & - & - & - & - \\
\hline
\end{tabular}

+ - difficult

- - part of the whole building out of service

* - use Table 6

\section{ASSESSMENT OF THE SOCIAL ASPECT OF SUSTAINABLE HOUSING IN THE CATEGORY $K_{5}$}

In the case under consideration, two subcategories $K_{51}$ and $K_{52}$ for the $K_{5}$ Maintenance and Maintenance category are listed, as well as the criteria by which they are assessed. Assessment of category $K_{5}$ is proposed to be rated by qualified assessment, which is based on the indicative ratings. For each criterion, it assumes the same scale of change of the criteria parameters from the highest standard (upper value) and ending at a certain fixed lower level. To assess the considered factor (criterion), depending on the existing state found, a discrete scale is used, consisting of $1 \div p$ levels for $p=5$. Due to the unified scale, it is not necessary to code measures in which individual features can be expressed. Moreover, this approach makes it 
easier for the user to carry out the assessment, especially since many of the assessed features are expressed on a qualitative scale that is difficult to measure and compare.

In addition, in multi-criteria analyses, which we are dealing with, an important problem is the unequal validity of the adopted criteria and how to include it in the assessment algorithm. To this end, the so-called weights (hierarchical coefficients) correcting values according to the preferences expressed by the expert (determined based on surveys) are introduced for evaluation:

$$
\lambda_{i j k} \in[0,1] \text { where } \sum_{i=1}^{m} \lambda_{i j k}=1 \text { for } j=1,2, \ldots, n_{i}, k=1,2, \ldots, n_{i j}
$$

The model adopted a weight scale: from 0.1 to 1.0 ( 0.1 - not important, ..., 1.0 - very important). The weights of the features taken into account in the assessment are determined based on surveys among users and experts in the field of construction. Surveys among users were carried out in two voivodships: Małopolskie and Śląskie in the years 2014-2015 in the form of questionnaires filled in by apartment users. In order to improve the credibility of the questionnaire surveys, they were carried out twice on a similar group of people. Each of the studies included 280 questionnaires [6]. The expert surveys were conducted through direct interviews. The group of respondents consisted of 17 experts related to the construction industry, including managers of works, design offices, and technical universities. Expert interviews allowed us to determine the weights of technical criteria that were difficult to assess by users.

Furthermore, the extremely different results of the surveys among users were rejected (The exclusion of data significantly different from the majority of the answers provided was based on checking the central tendency, dispersion, and asymmetry of the distribution of the results of the surveys and finding atypical observation results. On their basis, data significantly different from the majority of responses were excluded. The most common reason for the extremely different results was that one of the survey questions was not filled in or that all or part of the survey was incorrectly filled in.), while the remaining ones constituted the basis for establishing weights for subcategories and categories taken into account in the assessment of the social aspect of residential buildings.

The weight vectors calculated for category 5 have the values: $\lambda_{1, k}^{5}=(0,322 ; 0,318 ; 0,360) ; \lambda_{2, k}^{5}=(0,491 ; 0,509) ; \boldsymbol{L}_{j}^{5}=[0,505 ; 0,495]^{T}$.

Using the record in the form of a qualified assessment $O^{i}$, for $i=1, \ldots, m$, i $o_{j k}$, for $j=$ $1, \ldots, n_{i} ; k=1, \ldots, n_{i j}$ a rating matrix of category $\boldsymbol{O}^{i}$ is obtained and the weight matrix $\boldsymbol{\Lambda}^{i}$ assigned to it, where:

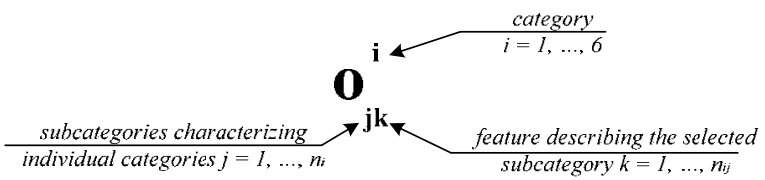

Using indexes for categories $K_{5}$ Maintenance and maintainability (Table 1) they will take the following values:

$n_{i}$ index values $\mathrm{j}$ : for $i=5: n_{i}=2$,

- $\quad n_{i j}$ index values $\mathrm{k}$ (when $i=5$ ): for $j=1: n_{5 j}=3$; for $j=2: n_{5 j}=2$, 
The matrix of assessment for $K_{5}$ Maintenance and maintainability and the matrix of weights assigned to it will have the form:

$$
\boldsymbol{O}^{5}=\left[\begin{array}{ccc}
o_{1,1}^{5} & o_{1,2}^{5} & o_{1,3}^{5} \\
o_{2,1}^{5} & o_{2,2}^{5} & 0
\end{array}\right], \quad \boldsymbol{\Lambda}^{5}=\left[\begin{array}{ccc}
\lambda_{1,1}^{5} & \lambda_{1,2}^{5} & \lambda_{2,3}^{5} \\
\lambda_{2,1}^{5} & \lambda_{2,2}^{5} & 0
\end{array}\right]
$$

Taking into account evaluation vectors that can be extracted from the matrix (2) by applying the adjusted index of the summation, a partial score is calculated for each of the two subcategories listed:

$$
\begin{gathered}
\text { for } K_{51}: O_{1}^{5}=\sum_{k=1}^{3} o_{1, k}^{5} \cdot \lambda_{1, k}^{5}=o_{1,1}^{5} \cdot \lambda_{1,1}^{5}+o_{1,2}^{5} \cdot \lambda_{1,2}^{5}+o_{1,3}^{5} \cdot \lambda_{1,3}^{5} \\
\quad \text { for } K_{52}: O_{2}^{5}=\sum_{k=1}^{2} o_{2, k}^{5} \cdot \lambda_{2, k}^{5}=o_{2,1}^{5} \cdot \lambda_{2,1}^{5}+o_{2,2}^{5} \cdot \lambda_{2,2}^{5}
\end{gathered}
$$

The next stage is to determine the adjusted index of summation for the vector value received in the previous calculation: $\boldsymbol{O}_{j}^{5}=\left[O_{1}^{5}, O_{2}^{5}\right]^{T}$. In addition, for two subcategories a weight vector has also been designated (by survey):

$$
\boldsymbol{L}_{j}^{5}=\left[L_{1}^{5}, L_{2}^{5}\right]^{T}
$$

For such a set value, we calculate:

$$
O_{C}^{5}=\sum_{j=1}^{2} O_{j}^{5} \cdot L_{j}^{5}=O_{1}^{5} \cdot L_{1}^{5}+O_{2}^{5} \cdot L_{2}^{5}
$$

Calculations should be carried out in parallel for the tested object and the reference object, which will ultimately determine the degree of compliance with the social properties of the analysed building. The reference building will be taken as an object that is the same in terms of shape, structure, function, and use as the building is assessed and meets the minimum requirements of the applicable regulations and standards. This building will constitute a comparative base for the analyses performed. In the presented article, the calculations for one of the six main categories, $K_{5}$ are demonstrated.

Ultimately, determining how to assess all six categories of the social aspect will allow the determination of the social quality index of residential buildings, which will give a convenient tool for their mutual comparison. The 5-point scale is an analogy to hotel stars, thanks to which it will be possible to classify residential objects for their attractiveness for the users. It will also help determine the market price of individual real estate.

\section{CONCLUSIONS}

The method of standardizing category assessments proposed in the work on the example of $K_{5}$ Maintenance and conservation is a contribution to the unification of the assessment of the social performance of sustainable construction. The established threshold values, the adopted scale of assessments for the considered criteria, as well as the weights assigned to individual criteria and subcategories are largely based on expert research. Thanks to the comprehensive social assessment of residential buildings, it is possible to obtain valuable information. The presented assessment of category $K_{5}$ allows identifying the weakest points of the examined real estate for the purpose of conducting operational activities there. Additionally, examining other, similar properties, allows placing its assessment in a five-point range, giving the user easy and clear information about the quality of conducted activities. The lowest-rated features also signal what needs to be improved first to increase the social quality indicator and thus the market value of the property. 
In summary, the article presents a method of assessing the social aspect of sustainable construction on the example of category $K_{5}$, which allows comparisons to be made in the operation of residential buildings. This assessment should be carried out between the tested building and the reference object, as well as between buildings constructed with different technologies. In the longer term, it will determine the aim of the planned refurbishment/modernization of the building, and help value the property.

\section{ACKNOWLEDGMENTS}

The work was carried out as part of statutory research no. 11.11.100.197 in the Department of Geomechanics, Civil Engineering and Geotechnics of Faculty of Mining and Geoengineering, AGH University of Science and Technology in Cracow.

ORCID

Aleksandra Radziejowska: https://orcid.org/0000-0002-3190-7129

\section{REFERENCES}

[1] M. Yılmaz, A. Bakış, Sustainability in Construction Sector, Procedia - Social and Behavioral Sciences, Vol. 195, pp. 2253-2262, July 2015.

https://doi.org/10.1016/j.sbspro.2015.06.312

[2] H. Zabihi, F. Habib, L. Mirsaeedie, Sustainability in Building and Construction: Revising Definitions and Concepts, International Journal of Emerging Sciences, Vol. 2, No. 4, pp. 570-578, December 2012.

[3] s. EN 15643-1, Sustainability of construction works - Sustainability assessment of buildings - Part 1: General framework, CEN, 2010.

[4] s. EN 15643-3, Sustainability of construction works - Assessment of buildings - Part 3: Framework for the assessment of social performance, 2012.

[5] s. EN 16309, Sustainability of construction works - Assessment of social performance of buildings - Calculation methodology, Standardization Committee, 2014+A1.

[6] A. Radziejowska, Z. Orłowski, Social utility properties of residential buildings in the light of the survey, Budownictwo i Architektura, Vol. 15, No. 2, pp. 73-78, 2016.

[7] l. Minister of Infrastructure, The Regulation on the technical conditions that should be met by buildings and their location (Dz. U. Nr 75, poz. 690 and its subsequent amendments), 2002.

[8] A. Kaklauskas, E. Zavadskas, S. Raslanas, Mulivariant design and multiple criteria analysis of building refurbishemnt, Energy and Buildings, Vol. 37, No. 4, pp. 361-372, 2005. https://doi.org/10.1016/i.enbuild.2004.07.005

[9] A.M.A.S. Langevine R., Decision support tool for the maintenance management of buildings, Joint International Conference on Computing and Decision Making in Civil and Building Engineering, Montreal-Canada, 14-16 June 2006.

[10] J. Baryłka, A. Baryłka, Exploitation of construction works, A guide for property owners and managers, Warsaw: Cetrum Rzeczoznawstwa Budowlanego Sp. z o.o., 2016. 
[11] A. Panek, Final Report No. project 8 T07G 004 21, A holistic method of assessing the impact of buildings on the environment taking into account the principles of sustainable development, Warsaw, 2005.

[12] J.M. Delgado, Sustainable Construction, Building Performance Simulation and Asset and Maintenance Management, Porto, Portugal: Springer, 2016.

[13] u. GUNB, "www.gunb.gov.pl/dziala/pliki/GI-modernizacja.pdf," 30.06.2017. [Online].

[14] INFOR.PL, "http://ksiegowosc.infor.pl/podatki/podatki-osobiste/vat/685085,Wykazrobot-zaliczanych-do-remontu-budynku-lub-lokalu-mieszkalnego.html," $\quad$ 21.08.2017. [Online].

[15] J. o. L. 2. p. 1. Article 5, Act of 7 July 1994. Construction Law, Warsaw, 2015. 